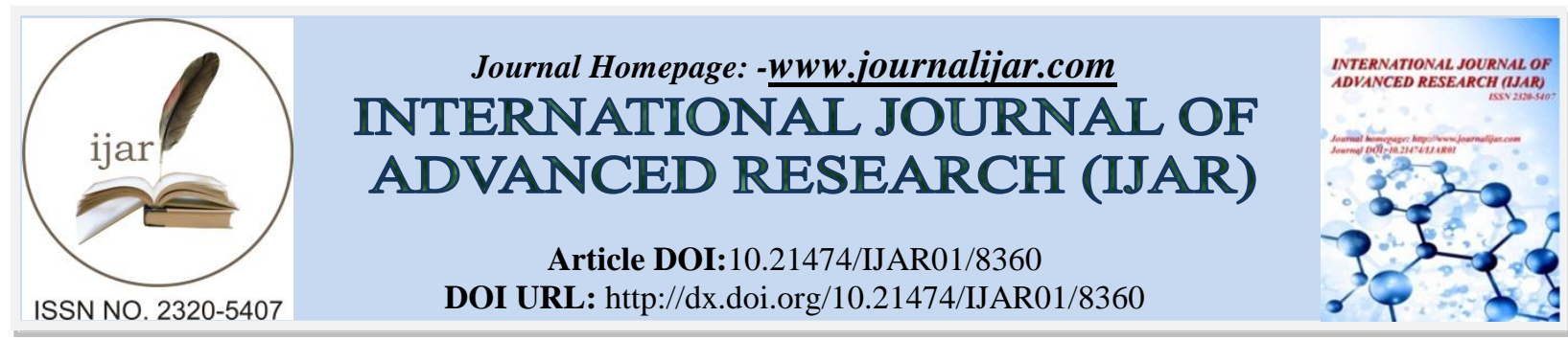

RESEARCH ARTICLE

\title{
THE POTENTIAL ANTIDEPRESSANT EFFECT OF ADENOSINE TRIPHOSPHATE AND CEREBROLYSIN ON RESERPINE INDUCED DEPRESSION IN MALE RATS.
}

Asmaa M. Moghazy ${ }^{1}$, Amel Abd El-Moneim Saad ${ }^{1}$ and Shimaa A. Haridy ${ }^{2}$.

1. Department of Hormonal evaluation, National Organization for Drug Control and Research. (NODCAR)

2. Department of Physiology, National Organization for Drug Control and Research .(NODCAR)

\section{Manuscript Info}

Manuscript History

Received: 08 November 2018

Final Accepted: 10 December 2018

Published: January 2019

Key words:-

Depression, Reserpine, Citalopram, ATP, Cerebrolysin.

\section{Abstract}

Background: Depression is a heterogeneous disorder that affects a person's mood, physical health and behavior. The present study aimed to investigate the potential antidepressant effect of adenosine triphosphate and cerebrolysin on reserpine induced depression in male rats through their effects on the levels of monoamine neurotransmitters and behavioral changes induced by reserpine.

Material and methods: This study was conducted on 50 adult male rats divided into five groups: the first is the control group (C); the second depressed group received reserpine only. The third, fourth and fifth groups included depressed rats treated orally with citalopram as classical drug, ATP and cerebrolysin, respectively. Behavioral test, forced swim test, as well as brain neurotransmitters levels such as (MDA, 8OHdG, 5HT, DA, DOPAC, HVA, ATP and $\mathrm{Na}^{+}-\mathrm{K}^{+}$ATPase) measured in brain tissue. Some biochemical parameters such as ALT, AST, TSH, $\mathrm{T}_{4}$ and testosterone were carried out in the serum.

Results: Data showed that reserpine induced depressive-like behavior in the forced swim test. Additionally, reserpine produced a significant increase in the level of MAD, 8OHdG, DOPAC, HVA, T 4 , ALT and AST and significant decreased in 5-HT, DA, TSH, Testosterone, ATP and $\mathrm{Na}^{+}-\mathrm{K}^{+}$ATPase as compared with control group. In contrast, cerebrolysin and ATP improve the behavioral parameters, decrease oxidative markers and increase neuronal function, liver function, and thyroid function and enhance testosterone level after 21 days of treatment in comparing with reserpine group and nearly to control group.

Conclusion: Cerebrolysin has pronounced effect than ATP, citalopram and ameliorate reserpine induced depression rats model.

Copy Right, IJAR, 2017,. All rights reserved.

\section{Introduction:-}

Depression could also be outlined in terms of a state of feeling unhappy. It may also be defined as a psychoneurotic disorder characterized by mental and functional activity, sadness, reduction in activity, difficulty in thinking, loss of concentration, perturbations in appetite, sleeping, and feelings of dejection, hopelessness and generation of suicidal tendencies (Sarko 2000). Patient with major depression have symptoms that reflect changes in brain neurotransmitter, specifically norepinephrine (NE), serotonin (5HT) and dopamine (DA) (Tripathi 2005).

Corresponding Author:-Asmaa M. Moghazy.

Address:-Department of Hormonal evaluation, National Organization for Drug Control and Research. 
Depression is a devastating and prevalent disease, with profound effects on neural structure and function. Major depressive disorder (MDD) is a recurrent, debilitating, and potentially life threatening illness. Depression is undoubtedly an extremely complex and heterogeneous condition (Logan 2004). Depression is a leading cause of morbidity worldwide (Valuck et al., 2012); it is the main cause of suicide as about $70 \%$ of all suicides are attributed to untreated depression (Wong et al., 2000). Antidepressants are widely used for treating major and minor depression (Hwang et al., 2008). Many antidepressant drugs are available with different pharmacological profiles from different classes: tricyclic antidepressants (TCAs), monoamine oxidase inhibitors (MAOIs) and selective serotonin reuptake inhibitors (SSRIs). There are some limitations with these drugs because there is a long delay before relief for symptoms, some patients with major depression are resistant to treatment, there is a risk to induce manic symptoms in patients with bipolar disorders and these drugs have no effect on the psychotic symptoms frequently associated to major depression (Quintin and Thomas 2004). Antidepressants drugs actually used in the treatment of depressive disorders need a longer duration to produce significant clinical effects or remain sometimes ineffective, there is a need to develop adjunctive therapeutic approaches that may help to hasten or to improve antidepressant effects (Venna et al., 2009).

Reserpine (Res.) is a potent naturally occurring alkaloid derived from roots of several members of Rauwolfia genus (Doyle et al., 1955) and was one of the first psychopharmacological drugs to treat the psychiatric diseases and also as an antihypertensive (Bleuler and Stoll 1955). It has been used clinically to control hypertension, schizophrenia, insomnia and insanity (Al-Bloushi et al., 2009). In later years, its use has been reduced because of precipitation of depression and extra pyramidal symptoms due to its central action (Sreemantula et al., 2004). Reserpine has the capability to deplete biogenic amines such as 5HT, NE and DA (Metzger et al., 2002).

Citalopram (Cit.), is one of the first-line selected serotonin reuptake inhibitor (SSRIs), is used to treat depression and anxiety disorders (Cipriani et al., 2012 and Davidson 2009). It previously reported that chronic citalopram treatment attenuates the NE response to handling stress in the basolateral amygdala due to sensitization of $\alpha_{2}$-adrenoceptors (Kawahara et al., 2007). Thus, the monoaminergic network, including the 5HT, DA, and NE pathways, is highly interconnected, and the interconnection might be modulated by chronic antidepressant treatment (Hamon and Blier 2013). Citalopram has fewer unwanted effects than older antidepressants. However, it's still possible for some people to experience side effects such as drowsiness and fatigue, sleep problems such as insomnia, mild nausea, diarrhea, constipation or stomach upset, agitation, anxiety, nervousness, tremor, disturbance in attention, decreased sex drive and increased sweating or urination.

Adenosine triphosphate (ATP) is well-known as the universal "energy currency" of living cells and it is also an important extracellular signaling molecule stems. Adenylyl compounds have profound effect on heart rate and cardiovascular function (Drury and Szent-Györgyi, 1929). ATP acts as a specific neurotransmitter in the nervous system (Burnstock 1972). Extracellular ATP has far more versatile functions in the neuronal information processing than a classical neurotransmitter, participating in pre- and post-synaptic neuromodulation, glia-neuron and glia-glia interactions. Importantly, purinergic signaling also plays a prominent role in the pathological brain and offers a number of target sites for therapeutic intervention in many diseases (Burnstock et al., 2011). ATP is released into the extracellular space in response to physiological neuronal activity and pathological signals such as hypoxia/hypoglycemia/ischemia, inflammation, metabolic and osmotic stress, and cellular damage.

Cerebrolysin (Cere,) is a nootropic peptidergic complex composed of purified porcine brain proteins and amino acids. It consists of low-molecular-weight biologically active neuropeptides which are able to cross the blood-brain barrier and act directly upon neurons (Zuber 1991 and Zhang et al., 2005). Cerebrolysin has a neurotrophic action and supports the maintenance and growth functions of neurons, prevents the neurological damage linked to the development of senile dementia and Alzheimer's disease, and maintains the neurons responsible for the activity of 5HT, choline and NA systems. Cerebrolysin prevents the forming of free-radicals, increases neurons viability and prevents neuronal cell death in cerebral hypoxia-ischemia. It improves memory through supporting the functions of the hippocampus which is the part of the brain where memories are stored (Sharp 2002 and Keilhoff et al., 2014). Recent studies have shown that animals treated with cerebrolysin achieve better learning performance within a few days, but the mechanism of this effect is complex (Zou et al., 2015). 


\section{Objective:-}

The aim of this study is to investigate the potential antidepressant effects of ATP and Cerebrolysin. To achieve this aim, we investigated the effects of these two drugs on reserpine induced depression in male rats as compared with the commonly used drug namely citalopram.

\section{Materials and Methods:- \\ Materials:-}

1. All chemicals, solvents (HPLC grade) and reagents were purchased from Sigma Aldrich.

2. Reserpine was a provided by Novartis Co. (Cairo, Egypt): it was provided as pure

3. Citalopram (Lundberck, Denemark).

4. ATP was obtained from Sigma Aldrich as a raw material.

5. Cerebrolysin (EVER Neuro Pharma GmbH, Unterach, Austria).The doses of reserpine, citalopram, adenosine triphosphate and cerebrolysin in the study were calculated based upon the human dose after conversion to that of rat according to (Paget and Barnes, 1964) conversion tables.

\section{Experimental animals:-}

Adult male rats $(180 \pm 20 \mathrm{~g})$ obtained from the National Organization for Drug Control and Research (NODCAR), Giza, Egypt, was used in this study. The rats were housed in wire mesh fence cages under standard conditions (temperature $25 \pm 2{ }^{\circ} \mathrm{C}, 12 \mathrm{~h}$ light and, $12 \mathrm{~h}$ darkness cycles). Animals were fed a pellet standard rat diet and water ad libitum. The study was conducted in accordance with the recommendations from the declaration of Helsinki on guiding principles in care and use of animals.

\section{Experimental design:-}

Rats were divided into five groups (10 rats each) and were treated as follows: group 1, normal control, animal received distilled water $(0.5 \mathrm{ml} / \mathrm{rats}$ orally); group 2 , depressed group which received reserpine only $(0.5 \mathrm{mg} / \mathrm{Kg}$ b.w); group 3, received citalopram (3.6 mg/kg orally), groups 4 received ATP $(2.7 \mathrm{mg} / \mathrm{kg} \mathrm{b.w}$ orally) and group 5 received cerebrolysin $(0.45 \mathrm{ml} / \mathrm{kg}$. b.w .i.p). Groups 3,4 and 5 received reserpine $(0.5 \mathrm{mg} / \mathrm{kg} \mathrm{b.w})$ after one hour daily for 21 days. On day 22, six rats were chosen from each group randomly to perform the behavioral tests, namely, Forced swim test (FST). After 24 hours, six rats from each group were chosen randomly and killed by decapitation. The brain was isolated, and washed with cold sterile physiological saline, blotted between two damp filter papers and stored at $-80^{\circ} \mathrm{C}$ until use for neurohemical analyses.

\section{Forced swim test (FST):-}

The forced swimming test was conducted according to the method described by Porsolt et al., 1977. Each rat was placed for $5 \mathrm{~min}$ in a cylindrical water tank $(70 \mathrm{~cm}$ high, $40 \mathrm{~cm}$ diameter), where the water level was about $40 \mathrm{~cm}$ and water temperature was maintained at $23-25^{\circ} \mathrm{C}$. The total duration of immobility of each animal was recorded. The tank was emptied and washed with fresh water flush between each rat to remove any traces of urine or feces.

\section{Blood samples and tissue collection:-}

At the end of the experiment, blood samples were collected from orbital plexus veins then the rats were sacrificed by cervical dislocation. Serum was separated and stored at $-20{ }^{\circ} \mathrm{C}$ until further biochemical analysis. Determination of thyroid stimulating hormone (TSH) according to Fisher 1996), determination of tetraiodothyroine ( $\mathrm{T}_{4}$ ) by ELISA technique according to (Thakur et al., 1997) and assay of testosterone according to (Tietz 1995). The levels of liver enzymes activity, namely Aspartate aminotransferase (AST) and Alanine aminotransferase (ALT) were determined by colorimetric method according to (Reitman and Frankel, 1957).

\section{Tissue collection:-}

Brain tissues were collected at the end of the experiment to determine the antioxidant levels of malondialdehyde (MDA) by HPLC according to (Karatepe, 2004). The level of 8-OHdG was determine according to (Lodovici et al., 1997). Determination of cell energy content (ATP) according to (Teerlink et al., 1993). The determination of 5HT in brain tissue according to (Pagel et al., 2000). $\mathrm{Na}^{+}-\mathrm{K}^{+}$ATPase activity was assayed according to (Taussky and Shorr, 1953) Assay of DA, Homovalinic acid (HVA) and 3, 4 dihydroxy phenyl acetic acid (DOPAC) by HPLC according to (Ahmed- Farid et al.,2016). 
Statistical analysis:

Data were expressed as means values $\pm \mathrm{SE}$ ( $\mathrm{n}=6$ rats) values in the different groups. Statistical differences between groups were evaluated by one-way analysis of variance (ANOVA) followed by Tukey Test using SPSS software program.

\section{Results:-}

The results of the FST are represented in Table 1 and Fig.1. Depression-like behavior induced by reserpine could be clearly demonstrated by the significant increase in the immobility and decrease in swimming and climbing time as compared with control with percentage change $52.14 \%,--29.65 \%$ and $-50 \%$ respectively. Treatment with citalopram, ATP and cerebrolysin caused significantly decrease in the immobility and significantly increase in swimming and climbing time when compared with reserpine group. Treament wih cerebrolysin induced non significant change in forced swim test parameter when compared with citalopram as refeerance drug.

Table 1:-Effect of Citalopram, Adenosine triphosphate and Cerebrolysin on Forced Swim Test in reserpine induced depressed rat model.

\begin{tabular}{|c|c|c|c|c|c|c|}
\hline \multirow{3}{*}{$\begin{array}{l}\text { Parameter } \\
\text { Animal } \\
\text { Group }\end{array}$} & \multicolumn{6}{|c|}{ Forced Swim Test } \\
\hline & \multicolumn{2}{|c|}{ Immobility } & \multicolumn{2}{|c|}{ Swimming } & \multicolumn{2}{|c|}{ Climbing } \\
\hline & Mean \pm SE & $\%$ Change & Mean \pm SE & $\%$ Change & Mean \pm SE & $\%$ Change \\
\hline Control & $117 \pm 4.13^{\mathrm{a}}$ & --------- & $199 \pm 6.95^{b}$ & -------- & $28 \pm 0.558^{\mathrm{d}}$ & -------- \\
\hline Res. & $178 \pm 5.18^{\mathrm{c}}$ & $52.14 \%$ & $140 \pm 4.75^{\mathrm{a}}$ & $-29.65 \%$ & $14 \pm 0.563^{\mathrm{a}}$ & $-50.00 \%$ \\
\hline Res+Cit. & $134 \pm 4.13^{\mathrm{ab}}$ & $14.53 \%$ & $194 \pm 6.93^{b}$ & $-2.51 \%$ & $27 \pm 0.428^{\mathrm{d}}$ & $-17.86 \%$ \\
\hline Res+ATP & $148 \pm 4.52^{b}$ & $26.50 \%$ & $165 \pm 4.11^{\mathrm{a}}$ & $-17.09 \%$ & $17 \pm 0.365^{b}$ & $-39.29 \%$ \\
\hline Res+Cereb & $127 \pm 4.14^{\mathrm{a}}$ & $8.55 \%$ & $195 \pm 7.94^{b}$ & $-2.01 \%$ & $23 \pm 0.764^{c}$ & $-17.86 \%$ \\
\hline
\end{tabular}

Data are expressed as Mean \pm SE ( $\mathrm{n}=6$ rats)

Means with different superscript letters are significant different at $\mathrm{p}<0.05$.

Data are analyzed with one way ANOVA followed by Tukey Test at $\mathrm{p}<0.05$.

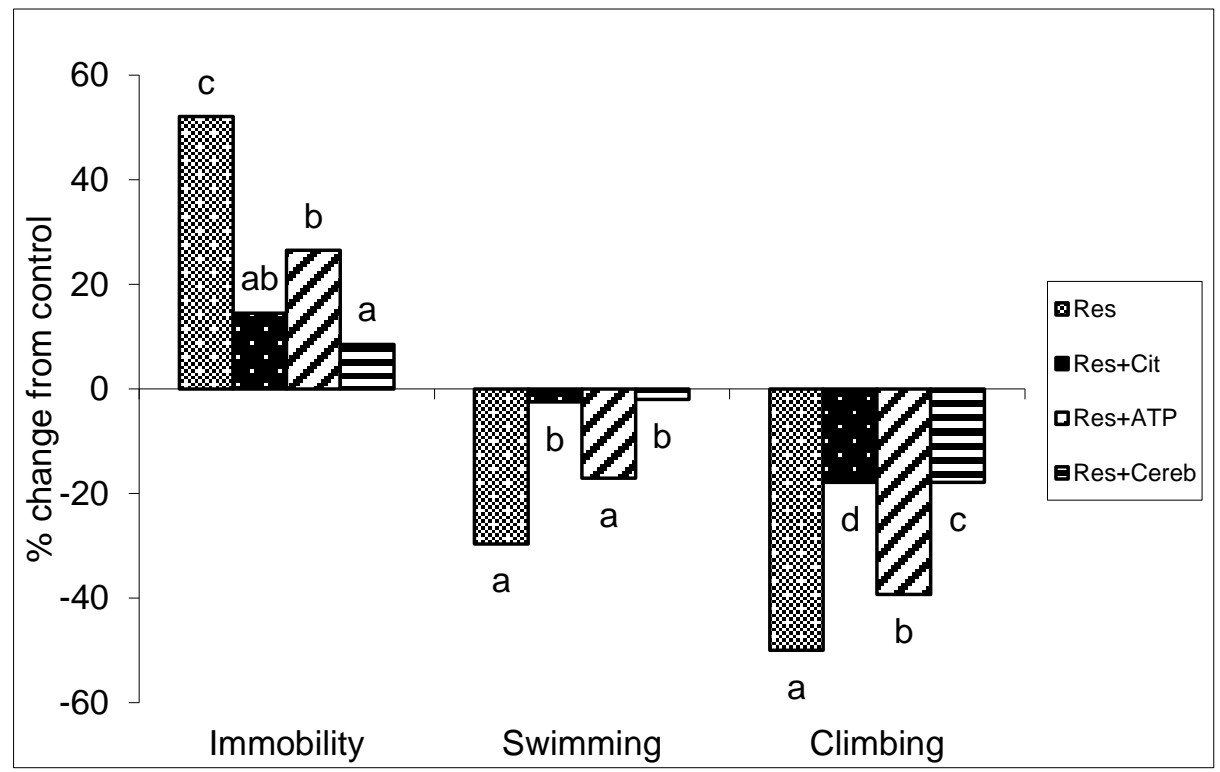

Fig. 1:-Percent changes induced in Forced Swim Test under the influence of different treatments with respect to control value.

Table 2 and Fig. 2 represent the results of oxidative stress as manifested by measuring MDA and 8-OHdG. Reserpine treatment caused a significant increase $(\mathrm{p}<0.05)$ in MDA and 8-OHdgG with percentage change $(78.48 \%$ and $47.02 \%$ respectively) as compared to control group. Treatment with citalopram as reference drug caused nonsignificant change in MDA and 8-OHdgG as compared with reserpine group. Treatment with ATP and cerebrolysin 
revealed a significant decline in the aforementioned parameters when compared with reserpine group. Treatment with cerebrolysin exhibited a significant decrease in MAD and 8-OHdG, while treatment with ATP revealed decline in the level of 8-OHdG when compared with citalopram.

Table 2:-Effect of Citalopram, Adenosine triphosphate and Cerebrolysin on brain oxidative stress markers (MDA and $8-\mathrm{OHdG}$ ) in reserpine induced depressed rat model.

\begin{tabular}{|l|c|c|c|c|}
\hline \multirow{2}{*}{$\begin{array}{l}\text { Anima } \\
\text { Group }\end{array}$} & \multicolumn{2}{|c|}{ MDA (nmol/g tissue) } & \multicolumn{2}{c|}{ 8-OHdG (pg/g tissue) } \\
\cline { 2 - 5 } & Mean \pm SE & \% Change & Mean \pm SE & \% Change \\
\hline Control & $32.560 \pm 2.024^{\mathrm{a}}$ & ------- & $219.318 \pm 4.954^{\mathrm{a}}$ & ------ \\
\hline Res & $58.113 \pm 1.563^{\mathrm{d}}$ & $78.48 \%$ & $322.443 \pm 8.821^{\mathrm{c}}$ & $47.02 \%$ \\
\hline Res+Cit. & $53.373 \pm 1.437^{\mathrm{cd}}$ & $63.92 \%$ & $323.308 \pm 7.128^{\mathrm{c}}$ & $47.42 \%$ \\
\hline Res+ATP & $48.560 \pm 0.918^{\mathrm{bc}}$ & $49.14 \%$ & $270.132 \pm 7.056^{\mathrm{b}}$ & $23.17 \%$ \\
\hline Res+Cereb. & $43.545 \pm 1.108^{\mathrm{b}}$ & $33.74 \%$ & $275.685 \pm 5.538^{\mathrm{b}}$ & $25.70 \%$ \\
\hline
\end{tabular}

Data are expressed as Mean \pm SE ( $\mathrm{n}=6$ rats)

Means with different superscript letters are significant different at $\mathrm{p}<0.05$.

Data are analyzed with one way ANOVA followed by Tukey Test at $\mathrm{p}<0.05$.

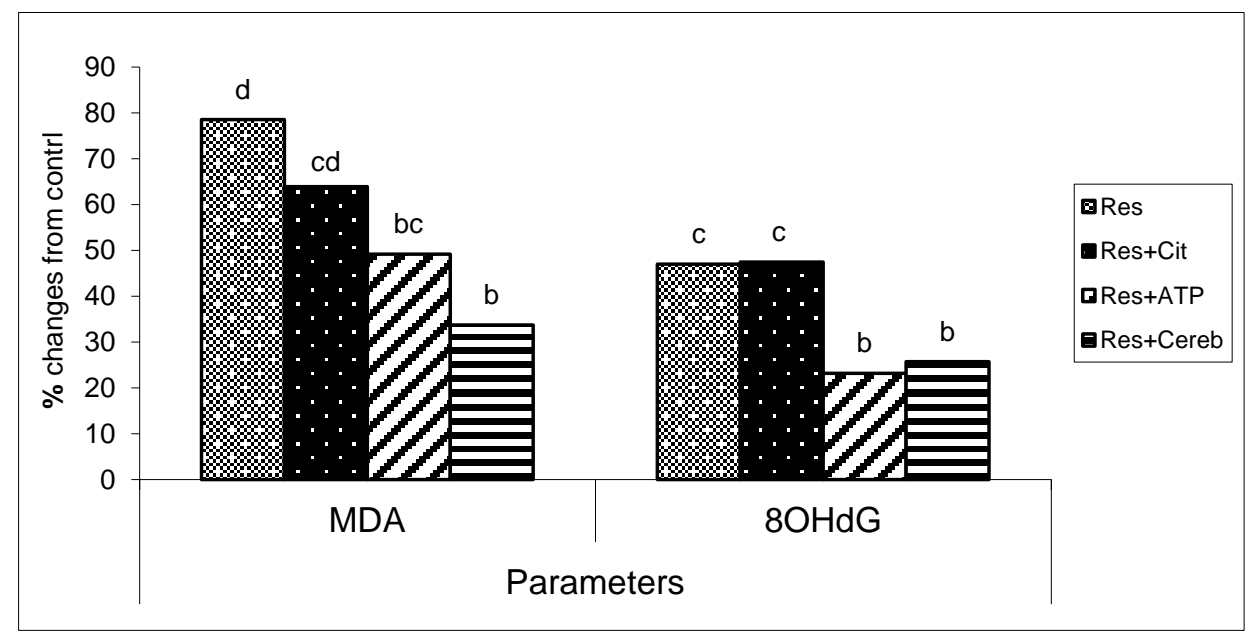

Fig. 2: Percent changes induced in MDA and 8-OHdG under the influence of different treatments with respect to control value.

Table 3 and Fig. 3 illustrate the results of monoamines as manifested by measuring 5HT, DA, DOPAC and HAV. Reserpine group revealed a significant decrease in DA and 5HT and increase in DOPAC and HAV with percentage change $(-34.12 \%,-35.26 \%, 70.18 \%$ and $61.89 \%$ respectively) when compared to control group $(\mathrm{p}<0.05)$. The treatment with citalopram and cerebrolysin exhibited a significant increase in 5HT and DA and decrease in DOPAC and HVA, while the group of rats treated with ATP elicited a significant decrease in 5HT, DOPAC, HVA and increase in DA when compared with reserpine group. Rats treated with cerebrolysin revealed a significant increase in 5HT and DA and decrease in HVA and non significant decrease in DOPAC when compared to citalopram group. On the other hand rats treated with ATP displayed a significant decrease in 5HTand non significant increase in DA and HVA and significant increase in DOPC when compared with citalopram group. Treated rat with cerebrolysin revealed the improvement in all monoamines when compared with ATP group. 
Table 3:-Effect of Citalopram, Adenosine triphosphate and Cerebrolysin on brain monoamines and their metabolites (5HT, DA, DOPAC and HVA) in reserpine induced depressed rat model.

\begin{tabular}{|c|c|c|c|c|c|c|c|c|}
\hline \multirow{2}{*}{$\begin{array}{l}\text { Parameters } \\
\text { Animal } \\
\text { Group }\end{array}$} & \multicolumn{2}{|c|}{$\begin{array}{c}5 \mathrm{HT} \\
(\mu \mathrm{g} / \mathrm{g} \text { tissue })\end{array}$} & \multicolumn{2}{|c|}{$\begin{array}{c}\text { DA } \\
(\mu \mathrm{g} / \mathrm{g} \text { tissue })\end{array}$} & \multicolumn{2}{|c|}{$\begin{array}{c}\text { DOPAC } \\
(\mu \mathrm{g} / \mathrm{g} \text { tissue })\end{array}$} & \multicolumn{2}{|c|}{$\begin{array}{c}\text { HVA } \\
(\mu \mathrm{g} / \mathrm{g} \text { tissue }) \\
\end{array}$} \\
\hline & Mean + SE & $\%$ change & Mean + SE & $\%$ change & Mean + SE & $\%$ change & Mean + SE & $\%$ change \\
\hline Control & $\begin{array}{c}0.337 \pm \\
0.009^{d}\end{array}$ & -------- & $\begin{array}{l}1.727 \pm \\
0.043^{\mathrm{d}}\end{array}$ & -------- & $\begin{array}{c}0.493 \pm \\
0.010^{\mathrm{a}} \\
\end{array}$ & -------- & $\begin{array}{c}0.412 \pm \\
0.011^{\mathrm{a}}\end{array}$ & -------- \\
\hline Res & $\begin{array}{c}0.222 \pm \\
0.003^{\mathrm{a}}\end{array}$ & $-34.12 \%$ & $\begin{array}{l}1.118 \pm \\
0.023^{\mathrm{a}}\end{array}$ & $-35.26 \%$ & $\begin{array}{c}0.839 \pm \\
0.015^{\mathrm{d}}\end{array}$ & $70.18 \%$ & $\begin{array}{c}0.667 \pm \\
0.019^{d}\end{array}$ & $61.89 \%$ \\
\hline Res+Cit. & $\begin{array}{c}0.300 \pm \\
0.007^{\mathrm{c}}\end{array}$ & $-10.98 \%$ & $\begin{array}{l}1.268 \pm \\
0.024^{\mathrm{b}}\end{array}$ & $-25.59 \%$ & $\begin{array}{c}0.605 \pm \\
0.014^{\mathrm{b}}\end{array}$ & $22.72 \%$ & $\begin{array}{c}0.520 \pm \\
0.014^{\mathrm{c}}\end{array}$ & $26.21 \%$ \\
\hline Res+ATP & $\begin{array}{c}0.272 \pm \\
0.003^{b}\end{array}$ & $19.29 \%$ & $\begin{array}{l}1.332 \pm \\
0.029^{b}\end{array}$ & $-22.87 \%$ & $\begin{array}{c}0.665 \pm \\
0.015^{\mathrm{c}} \\
\end{array}$ & $34.89 \%$ & $\begin{array}{l}0.482 \pm \\
0.014^{\mathrm{bc}}\end{array}$ & $16.99 \%$ \\
\hline Res+Cereb. & $\begin{array}{l}0.328 \pm \\
0.005^{\mathrm{d}}\end{array}$ & $-2.67 \%$ & $\begin{array}{l}1.555 \pm \\
0.039^{c}\end{array}$ & $-9.96 \%$ & $\begin{array}{c}0.597 \pm \\
0.012^{b}\end{array}$ & $21.10 \%$ & $\begin{array}{l}0.438 \pm \\
0.014^{\mathrm{ab}}\end{array}$ & $6.31 \%$ \\
\hline
\end{tabular}

Data are expressed as Mean $\pm \mathrm{SE}$ ( $\mathrm{n}=6$ rats)

Means with different superscript letters are significant different at $\mathrm{p}<0.05$.

Data are analyzed with one way ANOVA followed by Tukey Test at $\mathrm{p}<0.05$.

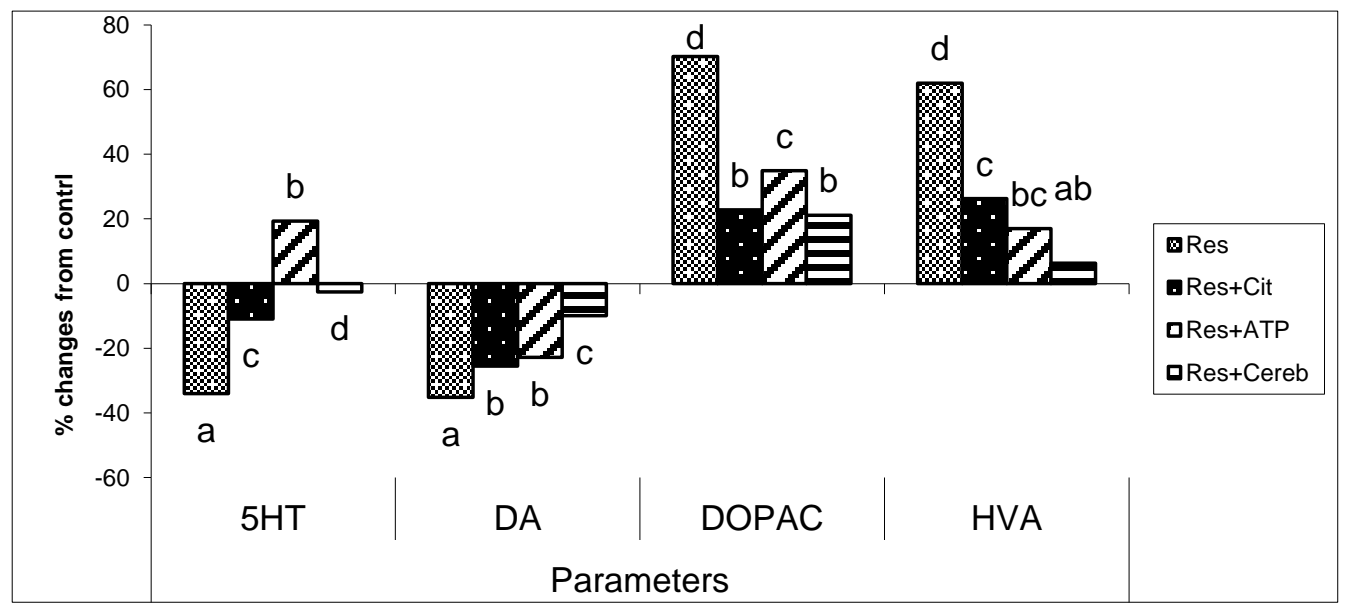

Fig. 3:-Percent changes induced in 5HT, DA, DOPAC and HVA under the influence of different treatments with respect to control value.

Tables 4 and Fig. 4 represent the results of thyroid gonadal (TSH and $\mathrm{T}_{4}$ ) and testosterone. Reserpine group caused a significant decrease in TSH and significant increase in $\mathrm{T}_{4}$ with percentage change $-35.62 \%$ and $69.54 \%$ as compared to normal control group at $\mathrm{p}<0.05$. While the treatment rats with citalopram as well as ATP revealed a significant increase in $\mathrm{TSH}$ and significant decrease in $\mathrm{T}_{4}$, while in rats treated with cerebrolysin caused a significant decrease in $\mathrm{T}_{4}$ and non significant decrease in TSH when compared with reserpine group. On the other hand, treatment with ATP caused a significant increase in TSH and non significant decrease in $\mathrm{T}_{4}$, while treatment with cerebrolysine caused non significant decrease in TSH and significant increase in $\mathrm{T}_{4}$ when compared with citalopram group. In the same table, the obtained data showed the result of testosterone. Treatment with reserpine revealed a significant decrease with percent change $-39.54 \%$ as compared with control group. Treatment with citalopram induced a significant decrease as compared with reserpine group. Treatment with ATP and cerebrolysin caused a significant increase when compared with citalopram. 
Table 4:-Effect of Citalopram, Adenosine triphosphate and Cerebrolysin on thyroid gland $\left(\mathrm{TSH}_{\mathrm{S}}\right.$ and $\left.\mathrm{T}_{4}\right)$ and Testosterone in reserpine induced depressed rat model.

\begin{tabular}{|c|c|c|c|c|c|c|}
\hline \multirow{2}{*}{$\begin{array}{l}\text { Parameter } \\
\text { Group }\end{array}$} & \multicolumn{2}{|c|}{$\mathrm{TSH}(\mu \mathrm{U} / \mathrm{ml})$} & \multicolumn{2}{|c|}{$\mathrm{T}_{4}(\mu \mathrm{g} / \mathrm{dl})$} & \multicolumn{2}{|c|}{ Testosterone (ng/ml) } \\
\hline & Mean + SE & $\%$ change & Mean + SE & $\%$ change & Mean + SE & $\%$ change \\
\hline Control & $0.842 \pm 0.018^{\mathrm{d}}$ & -------- & $6.378 \pm 0.155^{\mathrm{a}}$ & -------- & $2.370 \pm 0.023^{\mathrm{d}}$ & -------- \\
\hline Res & $0.542 \pm 0.012^{\mathrm{a}}$ & $-35.62 \%$ & $10.813 \pm 0.299^{d}$ & $69.54 \%$ & $1.433 \pm 0.021^{\mathrm{b}}$ & $-39.54 \%$ \\
\hline Res+Cit. & $0.618 \pm 0.014^{b}$ & $-26.60 \%$ & $8.305 \pm 0.174^{b}$ & $30.21 \%$ & $1.253 \pm 0.032^{\mathrm{a}}$ & $-47.13 \%$ \\
\hline Res+ATP & $0.697 \pm 0.015^{\mathrm{c}}$ & $-17.22 \%$ & $7.633 \pm 0.218^{b}$ & $19.68 \%$ & $1.822 \pm 0.027^{\mathrm{c}}$ & $-23.12 \%$ \\
\hline Res+Cereb. & $0.583 \pm 0.019^{\mathrm{ab}}$ & $-30.76 \%$ & $9.708 \pm 0.280^{c}$ & $52.21 \%$ & $1.448 \pm 0.028^{b}$ & $-38.90 \%$ \\
\hline
\end{tabular}

Data are expressed as Mean $\pm \mathrm{SE}(\mathrm{n}=6$ rats)

Means with different superscript letters are significant different at $\mathrm{p}<0.05$.

Data are analyzed with one way ANOVA followed by Tukey Test at $\mathrm{p}<0.05$.

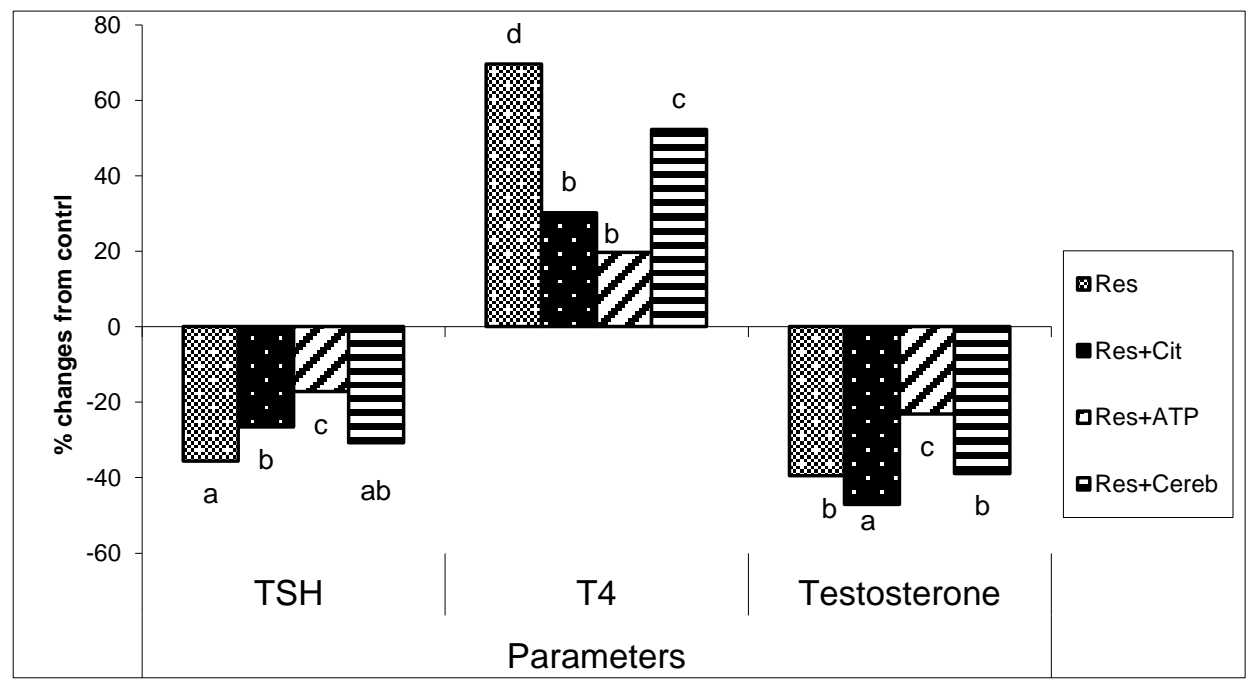

Fig. 4:-Percent changes induced in $\mathrm{TSH}, \mathrm{T}_{4}$ and testosterone under the influence of different treatments with respect to control value.

Table 5 and Fig. 5 represent the results of brain purenergic compounds and its degradable marker $\left(\mathrm{ATP}\right.$ and $\mathrm{Na}^{+}-\mathrm{K}^{+}$ ATPase). Reserpine treatment caused a significant decline in the aforementioned parameters as compared to control group at $(\mathrm{p}<0.05)$ with percentage change $(-41.30 \%$ and $-31.20 \%$ respectively). Meanwhile, the treatment of rats with ATP as well as cerebrolysin caused a significant increase in the aforementioned parameters when compared with reserpine group. On the other hand, the treatment of rats with ATP exhibited a significant increase in ATP and $\mathrm{Na}^{+}-\mathrm{K}^{+}$ATPase, while treated rat with cerebrolysin caused a significant increase in $\mathrm{Na}^{+}-\mathrm{K}^{+}$ATPase activity and increase in the level of ATP when compared with citalopram group.

Table 5:-Effect of citalopram, adenosine triphosphate and cerebrolysin on brain purenergic compounds and degradable marker (ATP and $\mathrm{Na}^{+}-\mathrm{K}^{+}$ATPase) in reserpine induced depressed rat model.

\begin{tabular}{|l|c|c|c|c|}
\multirow{2}{*}{$\begin{array}{l}\text { Animak } \\
\text { Group }\end{array}$} & \multicolumn{2}{|c|}{ ATP $(\mu \mathrm{g} / \mathrm{g}$ tissue) } & \multicolumn{2}{c|}{$\mathrm{Na}^{+}-\mathrm{K}+\mathrm{ATPase}(\mathrm{nmol} / \mathrm{g}$ tissue) } \\
\cline { 2 - 5 } & Mean+ SE & \% change & Mean+ SE & change \\
\hline Control & $23.793 \pm 0.674^{\mathrm{d}}$ & -------- & $447.448 \pm 8.190^{\mathrm{b}}$ & ------- \\
\hline Res & $13.967 \pm 0.469^{\mathrm{a}}$ & $-41.30 \%$ & $307.860 \pm 10.155^{\mathrm{a}}$ & $-31.20 \%$ \\
\hline Res+Cit. & $15.527 \pm 0.389^{\mathrm{ab}}$ & $-34.74 \%$ & $304.223 \pm 7.591^{\mathrm{a}}$ & $-32.00 \%$ \\
\hline Res+ATP & $18.673 \pm 0.535^{\mathrm{c}}$ & $-21.52 \%$ & $511.318 \pm 17.270^{\mathrm{c}}$ & $14.27 \%$ \\
\hline Res+Cereb. & $17.302 \pm 0.386^{\mathrm{bc}}$ & $-27.28 \%$ & $412.163 \pm 13.229^{\mathrm{b}}$ & $-7.89 \%$ \\
\hline
\end{tabular}

Data are expressed as Mean $\pm \mathrm{SE}$ ( $\mathrm{n}=6$ rats)

Means with different superscript letters are significant different at $\mathrm{p}<0.05$.

Data are analyzed with one way ANOVA followed by Tukey Test at $\mathrm{p}<0.05$. 


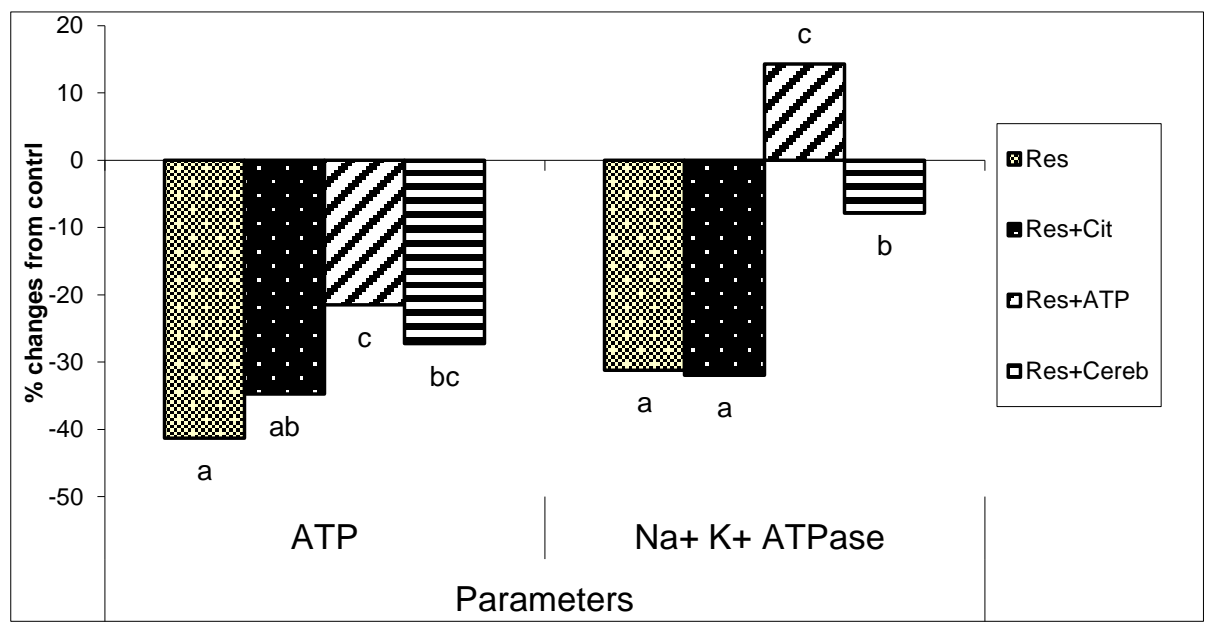

Fig. 5:- \% changes induced in ATP and $\mathrm{Na}^{+}-\mathrm{K}^{+}$ATPase activity under the influence of different treatments with respect to control value.

Table 6 and Fig. 6 illustrate that treatment of rats with reserpine for 21 days induced a significant increase in ALT and AST levels when compared with control group at $(\mathrm{p}<0.05)$ with percentage change $78.74 \%$ and $67.50 \%$ respectively. While, treatment of reserpinized rats with ATP and cerebrolysin caused a significant decrease in ALT and AST when compared with reserpine group. Meanwhile, reserpinized group treated with cerebrolysin induced a significant decrease in ALT and AST when compared with citalopram group.

Table 6:-Effect of Citalopram, Adenosine triphosphate and Cerebrolysin on liver enzymes activity in reserpine rats

\begin{tabular}{|l|c|c|c|c|}
\hline \multirow{2}{*}{$\begin{array}{l}\text { Anima- Parameter } \\
\text { Group }\end{array}$} & \multicolumn{2}{|c|}{ ALT (U/L) } & \multicolumn{2}{c|}{ AST (U/L) } \\
\cline { 2 - 5 } & Mean+ SE & $\%$ change & Mean+ SE & \% change \\
\hline Control & $26.475 \pm 0.613^{\mathrm{a}}$ & ------ & $23.302 \pm 0.541^{\mathrm{a}}$ & $----^{\mathrm{a}}$ \\
\hline Res & $47.322 \pm 2.380^{\mathrm{d}}$ & $78.74 \%$ & $39.032 \pm 1.410^{\mathrm{d}}$ & $67.50 \%$ \\
\hline Res+Cit. & $42.240 \pm 0.685^{\text {cd }}$ & $59.47 \%$ & $34.488 \pm 1.118^{\text {cd }}$ & $48.00 \%$ \\
\hline Res+ATP & $39.255 \pm 0.781^{\mathrm{bc}}$ & $48.27 \%$ & $32.183 \pm 0.937^{\mathrm{bc}}$ & $38.12 \%$ \\
\hline Res+Cereb. & $35.418 \pm 1.141^{\mathrm{b}}$ & $33.78 \%$ & $28.922 \pm 1.389^{\mathrm{b}}$ & $24.12 \%$ \\
\hline
\end{tabular}

Data are expressed as Mean \pm SE ( $n=6$ rats)

Means with different superscript letters are significant different at $\mathrm{p}<0.05$.

Data are analyzed with one way ANOVA followed by Tukey Test at $\mathrm{p}<0.05$.

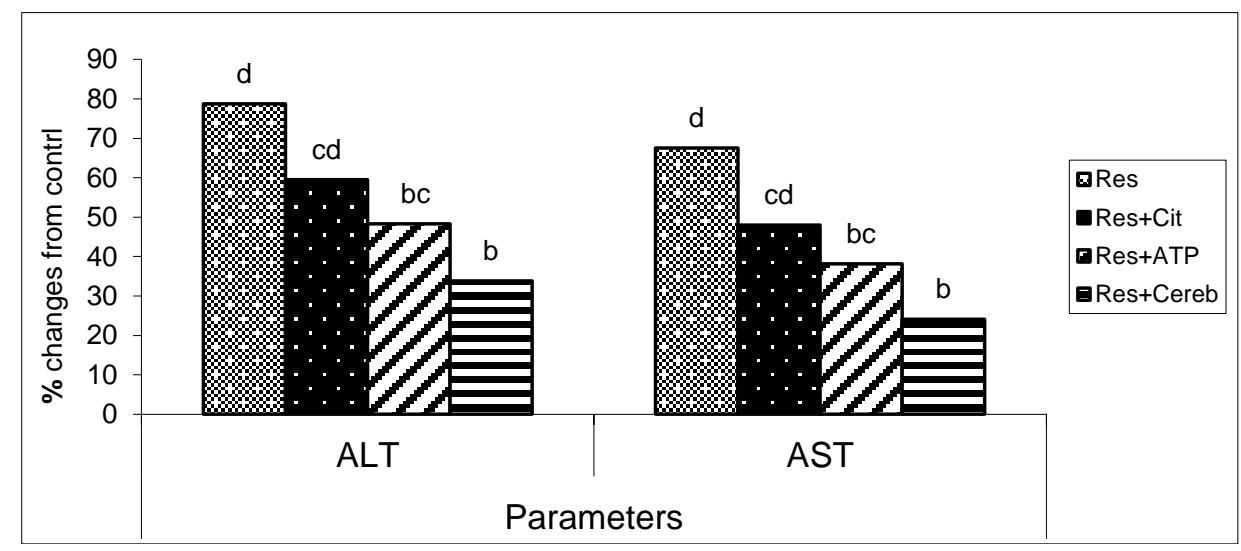

Fig. 6:-Percent changes induced in ALT and AST enzymes activity under the influence of different treatments with respect to control value. 


\section{Discussion:-}

Depression is a devastating and current disease, with profound effects on neural structure and function. This study was planned to investigate the potential antidepressant effects of ATP and cerebrolysin in a reserpine model of depression against citalopram as a classical drug of depression. The present study showed that, oral administration of reserpine induced a significant increase in immobility and decreases in swimming and climbing time. This finding agrees with (Nagakura et al., 2009, Rojas-Corrales et al.,2004 and Kandel 2000), they reported that reserpine is a vesicular monoamine re-uptake blocker, which depletes monoamines in the brain, and produces depression-like syndrome in animals. The obtained data showed that, the treatment of depressed rats with citalopram, ATP and cerebrolysin resulted in a significant reduction in the immobility time and increase in swimming and climbing time respectively in comparing to its level of the reserpine group. This observation may be due to the improved in the monoamine level, which normalized via a reference drug pathway as an SSRI and cerebrolysin as a ploy peptide growth factor which stimulate neuronal function. In addition, ATP acts as neuromodulator which modulate monoamines and cell function. This finding agrees with (Cipriani et al., 2012; Burnstock et al., 2011; Sharp2002 and Keilhoff et al., 2014). The current results reveal that, oral administration of reserpine induced a significant increase in oxidative stress, such as MDA and $8 \mathrm{OHdG}$ as compared to control group. This finding is agrees with (Lopresti et al., 2014) who reported that depression is characterized by increased oxidative stress, as indicated by higher levels of MDA and 8-OHdG. (Li et al., 2013 and 2015) reported that MDA is one of the major metabolites induced by free radicals, and it can cause denaturation of biomembranes and mutation of DNA via increase level of 8-OHdG. Treatment with ATP caused an decline in the level of MDA and 8-OHdG as compared with reserpine group. This may be due to the ATP decrease production of ROS, decrease oxidative stress and increase activities of enzymes involved in the respiratory chain, increase ATP production and improve mitochondrial function. This finding agrees with (Van Remmen, and Richardson, 2001) who reported that the mitochondrial damage caused by oxidative stress could result in reduced ATP production and compromised cell function. Treatments with cerebrolysin caused decreases in the level of MDA and $8-\mathrm{OHdG}$ when compared to reserpine group. This finding agrees with (Guzmán et al., 2016) who recorded that, administration of cerebrolysin prevents the formation of free radical and oxidative stress due to increased metabolism of DA. (An et al., 2016) found that cerebroprotein hydrolysate significantly decreased MDA levels in the brain tissue of rat, indicating that cerebroprotein hydrolysate may significantly improve the scavenging of oxygen free radicals in brain tissue.

The results of the current study revealed that, oral administration of reserpine resulted in a significant decrease in 5HT and DA and increase in DOPAC and HVA respectively as compared to their levels of control rats. This finding agrees with (Dhingra and Sharma, 2006) who demonstrated that reserpine produces a significant depletion in biogenic amines (NE, 5HT and DA) rats' brains. Moreover, (Yoshitake 2004) reported that reserpine reduced the extracellular 5HT, NE and DA concentrations and (Ahmed, et al., 1997) reported that reserpine impairs the storage of biogenic amines resulting in depletion of NE, DA, and 5HT in both the central and peripheral nervous systems consequently disturbs the digestive system and decreases food intake. One or more mechanisms could be responsible for lowering these monoamines in the brains of the rats treated with reserpine. It has been reported that reserpine exerts its depleting effect specifically by inhibiting the adenosine triphosphate- $\mathrm{Mg}^{2+}$-dependent incorporation of biogenic amines into their storage vesicles (Carlsson et al.,1963); secondly, it was found that reserpine binds irreversibly to a vesicular transporter protein, thereby disrupting storage of catecholamines (DA and NE) and 5-HT; thirdly, reserpine blocks vesicular monoamine transporter 2 (VMAT2) resulting in the depletion of monoamines; and it is well known that VMATs are involved in the presynaptic packaging of monoaminergic neurotransmitters into storage granules (Lohoff et al., 2008) The data of this study shows that, treatment with citalopram caused an improvement in the level of 5-HT, DA, DOPAC and HVA due to the mode of action of citalopram which act as SSRI. This finding agrees with (Wessling and Ramsberg 2008) they reported that, the antidepressant drug inhibits reuptake of neurotransmitters through selective receptors thereby increasing the concentration of specific neurotransmitter around the nerves in the brain. Meanwhile, treatment with cerebrolysin causes a significant increase in 5-HT and DA and decrease in DOPAC and HAV as compared with reserpine group. This finding agrees with that of (Bannerman, et al., 2008, Novak, et al., 2009 and (García, et al., 2011) they reported that cerebroprotein hydrolysate can affect the respiratory chain by increasing the utilization of oxygen and glucose in the brain, subsequently, increasing the antioxidant capacity of brain tissues and the ability of the body to handle stress, improving energy metabolism in the brain, alleviating damage of brain tissues, and promoting recovery of brain function., it has a brain-strengthening, intelligence-improving, and brain-damage-repairing effects. The obtained data showed that oral administration of reserpine caused a significant decrease in TSH and an increase 
in $\mathrm{T}_{4}$ when compared with the control group. This finding agrees with (Bradham et al., 1998) who reported that, $\mathrm{T}_{4}$ increase in depression is based on the increase of cortisol (hypercortisolism of depression), that believed lead to an activation of the hypothalamic neurons, which produce the thyrotrophin releasing Hormone (TRH) and consequently, affected thyroid function. Some studies have found a correlation between the severity of depression and serum T4 level (Khalil and Richa 2011) reported that SSRI antidepressant drugs may alter TSH and $\mathrm{T}_{4}$ levels without having major clinical implications for thyroid suggestions coincide with the results of the present study. The data of this study showed that, the treatment with ATP induce increase in TSH and decline in $\mathrm{T}_{4}$ when compared with reserpine group. This observation may be due to ATP play important role in neurotransmitter and compensated the decline of ATP which result from hyperthyroidism induces with reserpine.

In the present study, administration of reserpine induced a significant decrease in testosterone level. This finding agrees with (Alderson and Baum 1981). who reported that testosterone has been shown to affect a number of monoamines implicated in mental illness. In relation to depression, testosterone can enhance dopamine release in the mesolimbic system which may protect against depression-induced anhedonia and the associated decrease in dopamine activity in reward-related brain pathways. Additionally, intra-nasal administration of testosterone in intact male rodents increased dopamine and 5-HT release in the neostriatum and nucleus accumbens (de Souza Silva et al., 2009). The obtained data showed that, treatment with ATP increase level of testosterone as comparing with reserpine group.

The results of the current study show that, the administration of reserpine caused a significant decrease in the level of ATP and $\mathrm{Na}^{+} . \mathrm{K}^{+}$ATPase. This finding is agrees with (Nagakura et al., 2009 and Rojas-Corrales et al., 2004) they reported that, reserpine is an inhibitor of VMAT2 and interferes with the storage of monoamines by blocking the ATP-dependent uptake mechanism of the storage organelles. (Xie 1989) reported also, the free radicals and its metabolites can cause damage to the membrane of cells and decrease the activity of widely distributed $\mathrm{Na}^{+}-\mathrm{K}^{+}$ATPases. This can catalyze the hydrolysis of ATP and promote the release of free energy stored in ATP to drive the active transport of $\mathrm{Na}+, \mathrm{K}+$, and other substances. An addition to the decrease of ATP in mitochondria is associated with excessive production of ROS and increasing of oxidative stress. The disrupted function of mitochondria and an insufficient oxygen radical degradation increase the concentration of ROS in the organism that consequently causes lipid, protein, and DNA damage. The obtained results showed that treatment with cerebrolysin and ATP increased significantly in the level of ATP and $\mathrm{Na}^{+} . \mathrm{K}^{+}$ATPase activity as compared with reserpine group. This finding is agrees with (Teng et al., 2014) who reported that, cerebroprotein hydrolysate can increase $\mathrm{Na}^{+}$- $\mathrm{K}^{+}$ATPase activity to promote the release of neurotransmitters associated with learning and memory, regulate the excitability of neurons, enhance brain function, and improve the quality and quantity of brain activity, consistent with numerous prior reports . Meanwhile the treatment with ATP activity could be attributed to the increased level of ATP and $\mathrm{Na}^{+}-\mathrm{K}^{+}$ ATPase may be due to increased level of ATP inside the cell function and improving mitochondrial function. The data of the current study revealed that, oral administration of reserpine caused significantly increase in ALT and AST as compared to control group. This data agrees with ( Ahmed-Farid el al., 2016) who reported that, Reserpine administration is known to disrupt the permeability of the plasma membrane, causing leakage of these enzymes from the liver into serum. The obtained data showed that, treatment with ATP and cerebrolysin induced significantly decrease in liver enzymes, may be due to ATP and cerebrolysin decrease oxidative stress.

\section{Conclusion:-}

Our study concluded that, reserpinized rats showed behavioral signs of depression compared to the control group. The reserpinized groups received three different potential antidepressant drugs (Citalopram, ATP and cerebrolysin).Cerebrolysin has pronounced effect than ATP and citalopram and we need to highlight that further investigation to determine the mode of action of cerebrolysin and ATP on other animal model for depression.

\section{Competing interests:-}

The authors report no conflicts of interest in this work.

\section{Authors' contributions:-}

Asmaa Moghazy, Amel Abd El-Moneim Saad and Shimaa A. Haridy designed the study and per-formed the experiments and conducted the data analysis, Asmaa Moghazy, Amel Abd El-Moneim Saad and Shimaa A. Haridy participated in drafting the paper, wrote the manuscript and approved the manuscript. 


Abbreviations:-
\begin{tabular}{|l|l|}
\hline Norepinephrine & NE \\
Serotonin & 5HT \\
Dopamine & DA \\
Major depressive disorder & MDD \\
Tricyclic antidepressants & TCAs \\
Monoamine oxidase inhibitors & MAOIs \\
Selective serotonin reuptake inhibitors & SSRIs \\
Citalopram & Cit \\
Cerebrolysin & Cere \\
Adenosine triphosphate & ATP \\
Forced swim test & FST \\
Thyroid stimulating hormone & TSH \\
Tetraiodothyroine & T4 \\
Aspartate aminotransferase & AST \\
Alanine aminotransferase & ALT \\
Malondialdehyde & MDA \\
Homovalinic acid & HVA \\
3,4 dihydroxy phenyl acetic acid & DOPAC \\
\hline
\end{tabular}

\section{References:-}

1. Sarko, J. (2000). Antidepressants, old and new. A review of their adverse effects and toxicity in overdose. Emergency Medicine Clinics of North America, 18(4): 637-654.

2. Tripathi, K.D. (2005). Relevant physiology of urine formation; essentials of medical pharmacology. Arch Ital Urol Androl, 77, pp.557-560.

3. Logan, A.C. (2004). Omega-3 fatty acids and major depression: a primer for the mental health professional. Lipids in health and disease, 3(1):25-33

4. Valuck, R.J., Anderson, H.O., Libby, A.M., Brandt, E., Bryan, C., Allen, R.R., Staton, E.W., West, D.R. and Pace, W.D. (2012). Enhancing electronic health record measurement of depression severity and suicide ideation: a Distributed Ambulatory Research in Therapeutics Network (DARTNet) study. The Journal of the American Board of Family Medicine, 25(5):582-593.

5. Wong, M.L., Kling, M.A., Munson, P.J., Listwak, S., Licinio, J., Prolo, P., Karp, B., McCutcheon, I.E., Geracioti, T.D., DeBellis, M.D. and Rice, K.C. (2000). Pronounced and sustained central hypernoradrenergic function in major depression with melancholic features: relation to hypercortisolism and corticotropin-releasing hormone. Proceedings of the National Academy of Sciences, 97(1):325-330.

6. Hwang, J., Zheng, L.T., Ock, J., Lee, M.G., Kim, S.H., Lee, H.W., Lee, W.H., Park, H.C. and Suk, K. (2008). Inhibition of glial inflammatory activation and neurotoxicity by tricyclic antidepressants. Neuropharmacology, 55 (5), pp.826-834.

7. Quintin, P. and Thomas, P. (2004). Efficacy of atypical antipsychotics in depressive syndromes. L'Encephale, 30(6):583-589.

8. Venna, V.R., Deplanque, D., Allet, C., Belarbi, K., Hamdane, M. and Bordet, R. (2009). PUFA induce antidepressant-like effects in parallel to structural and molecular changes in the hippocampus. Psychoneuroendocrinology, 34(2):199-211.

9. Doyle, A.E., McQueen, E.G. and Smirk, F.H. (1955).Treatment of hypertension with reserpine, with reserpine in combination with pentapyrrolidinium, and with reserpine in combination with veratrum alkaloids. Circulation, 11(2):170-181.

10. Bleuler, M. and Stoll, W.A. (1955). Clinical use of reserpine in psychiatry: comparison with chlorpromazine. Annals of the New York Academy of Sciences, 61(1):167-173.

11. Al-Bloushi, S., Safer, A.M., Afzal, M. and Mousa, S.A. (2009). Green tea modulates reserpine toxicity in animal models. The Journal of Toxicological Sciences, 34(1):77-87.

12. Sreemantula, S., Boini, K.M. and Nammi, S. (2004). Reserpine methonitrate, a novel quaternary analogue of reserpine augments urinary excretion of VMA and 5-HIAA without affecting HVA in rats. BMC Pharmacology, 4(1):30. 
13. Metzger, R.R., Brown, J.M., Sandoval, V., Rau, K.S., Elwan, M.A., Miller, G.W., Hanson, G.R. and Fleckenstein, A.E. (2002).Inhibitory effect of reserpine on dopamine transporter function. European journal of pharmacology, 456(1-3):39-43.

14. Cipriani, A., Purgato, M., Furukawa, T.A., Trespidi, C., Imperadore, G., Signoretti, A., Churchill, R., Watanabe, N. and Barbui, C. (2012). Citalopram versus other anti-depressive agents for depression. The Cochrane Database of Systematic Reviews, 7, p.CD006534.

15. Davidson, J.R. (2009). First-line pharmacotherapy approaches for generalized anxiety disorder. Journal of Clinical Psychiatry. 70 (Suppl 2):25-31

16. Kawahara, Y., Kawahara, H., Kaneko, F. and Tanaka, M. (2007). Long-term administration of citalopram reduces basal and stress-induced extracellular noradrenaline levels in rat brain. Psychopharmacology (Berl). 194(1):73

17. Hamon, M. and Blier, P. (2013). Monoamine neurocircuitry in depression and strategies for new treatments. Progress in Neuro-psychopharmacology and Biological Psychiatry, 45:54-63.

18. Drury, A.N. and Szent-Gyorgyi, A (1929) The physiological action of adenine compounds with especial reference to their action on the mammalian heart. J. Physiol.(Lond), 68: 214-237.

19. Burnstock, G (1972). Purinergic nerves. Pharmacol Rev, 24: 509-81

20. Burnstock, G, Krugel, U, Abbracchio, M.P.and Illes, P (2011). Urinergic signalling: from normal behaviour to pathological brain function. Prog Neurobiol., 95(2):229-74.

21. Zuber, V.L. (1991). The effect of cerebrolysin on the metabolism of brain phospholipids in growing animals with experimental demyelination. Nervnaia Sistema, 30:85-90.

22. Zhang, H., Zhang, X. and Xu, B. (2005). Analysis and determination of biological activity of short-chain peptides from porcine brain hydrolysate. Journal of Pharmaceutical and Biomedical Analysis, 37(2):333-339.

23. Sharp, N., Ellard, M., Hirschowitz, L., Malthouse, S. and Johnson, N. (2002). Successful microwave ablation of endometrial carcinoma. BJOG: An International Journal of Obstetrics \& Gynaecology, 109(12), pp.1410-1412.

24. Keilhoff, G., Lucas, B., Pinkernelle, J., Steiner, M. and Fansa, H. (2014). Effects of cerebrolysin on motorneuron-like NSC-34 cells. Experimental Cell Research, 327(2):234-255.

25. Zou, Y., Feng, W., Wang, W., Chen, Y., Zhou, Z., Li, Q., Zhao, T., Mao, G., Wu, X. and Yang, L., (2015). Protective effect of porcine cerebral hydrolysate peptides on learning and memory deficits and oxidative stress in lead-exposed mice. Biological Trace Element Research, 168(2):429-440.

26. Paget, G.E. and Barnes, J.M. (1964). Toxicity Testing. In: Evaluation of Drug Activities Pharmacometics (Laurence, D.R. and Bacharach, A.L., eds.). Academic Press, London,UK, pp.1-13

27. Porsolt, R.D., Le Pichon, M. and Jalfre, M. (1977). Depression: a new animal model sensitive to antidepressant treatments. Nature, 266 (5604):730-732.

28. Fisher, D.A. (1996). Physiological variations in thyroid hormones: physiological and pathophysiological considerations. Clinical Chemistry, 42(1):135-139.

29. Thakur, C.H. Saikia, T.C. and Yadav, R.N.S. (1997). Total Serum Levels of Triiodothyronine (T 3) Thyroxine (T 4) and Thyrotropine (TSH) in School going Children of Dibrugarh District: An Endemic Goitre Region of Assam. Indian Journal of Physiology and Pharmacology, 41:167-170.

30. Tietz, N.W. (1995) ed., Clinical Guide to Laboratory Tests, 3rd Edition, W.B. Saunders, Co., Philadelphia,pp. 578-580

31. Reitman, S. and Frankel, S. (1957). A colorimetric method for the determination of serum glutamic oxalacetic and glutamic pyruvic transaminases. American Journal of Clinical Pathology, 28(1):56-63.

32. Karatepe, M.,( 2004). Simultaneous determination of ascorbic acid and free malondialdehyde in human serum by HPLC-UV. Lc Gc North America, 22(4), pp.362-365.

33. Lodovici, M., Casalini, C, Briani, C. and Dolara, P. (1997). Oxidative liver DNA damage in rats treated with pesticide mixtures. Toxicology; 117:55-60.

34. 34-Teerlink, T., Hennekes, M, Bussemaker, J. and Groeneveld, J. (1993). Simultaneous determination of creatine compounds and adenine nucleotides in myocardial tissue by high-performance liquid chromatography. Analytical Biochemistry, 214 (1):278-83.

35. Pagel, P., Blome, J. and Wolf, H. U. (2000). High-performance liquid chromatographic separation and measurement of various biogenic compounds possibly involved in the pathomechanism of Parkinson's disease. Journal of Chromatography B: Biomedical Sciences and Applications, 746(2): 297-304.

36. Taussky, H.H. and Shorr, E.E. (1953). A microcolorimetric method for the determination of inorganic phosphorus. The Journal of Bioliogical Chemistry, 202 (2): 675-285. 
37. Ahmed-Farid, O., Ahmed, R. and Saleh, D., 2016. Combination of resveratrol and fluoxetine in an acute model of depression in mice: Prevention of oxidative DNA fragmentation and monoamines degradation. $J$ Appl Pharm Sci, 6, pp.1-7.

38. Nagakura, Y., Oe, T., Aoki, T. and Matsuoka, N., 2009. Biogenic amine depletion causes chronic muscular pain and tactile allodynia accompanied by depression: a putative animal model of fibromyalgia. Pain, 146(1-2), pp.26-33.

39. Rojas-Corrales, M.O., Berrocoso, E., Gibert-Rahola, J. and Micó, J.A.. (2004). Antidepressant-Like Effect of tramadol and its Enantiomers in Reserpinized Mice: Comparativestudy with Desipramine, Fluvoxamine, Venlafaxine and Opiates. Journal of Psychopharmacology, 18(3), pp.404-411.

40. Kandel ER (2000) Disorders of mood: depression, mania, and anxiety disorders. In: Kandel ER (ed) Principles of neural science, 4th edn. McGraw-Hill Companies, New York, pp 1216-1217

41. Lopresti, A.L., Maker, G.L., Hood, S.D. and Drummond, P.D., 2014. A review of peripheral biomarkers in major depression: the potential of inflammatory and oxidative stress biomarkers. Progress in NeuroPsychopharmacology and Biological Psychiatry, 48, pp.102-111.

42. Li, Y.S., Hong, Y.F., He, J., Lin, J.X., Shan, Y.L., Fu, D.Y., Chen, Z.P., Ren, X.R., Song, Z.H. and Tao, L. (2013). Effects of magnolol on impairment of learning and memory abilities induced by scopolamine in mice. Biological and Pharmaceutical Bulletin, 36(5):764-771.

43. Li, C., Wang, Q., Li, L., Liu, Y. and Diao, H. (2015). Arachidonic acid attenuates learning and memory dysfunction induced by repeated isoflurane anesthesia in rats. International Journal of Clinical and Experimental Medicine, 8(8):12365.

44. Van Remmen, H. and Richardson, A. (2001). Oxidative damage to mitochondria and aging. Experimental Gerontology, 36(7):957-968.

45. Guzmán, D.C., Brizuela, N.O., Herrera, M.O., García, E.H., Mejía, G.B., Olguín, H.J., Peraza, A.V., Attilus, J. and Ruíz, N.L., (2016). Effect of cerebrolysin on dopaminergic neurodegeneration of rat with oxidative stress induced by 3-nitropropionic acid. Acta Pharmaceutica, 66(3), pp.443-448.

46. An, L., Han, X., Li, H., Ma, Y., Shi, L., Xu, G., Yuan, G., Sun, J., Zhao, N., Sheng, Y. and Wang, M. (2016). Effects and mechanism of cerebroprotein hydrolysate on learning and memory ability in mice. Genet Mol Res, 15(3).

47. Dhingra, D. and Sharma, A. (2006). Antidepressant-like activity of Glycyrrhiza glabra L. in mouse models of immobility tests. Progress in Neuro-Psychopharmacology and Biological Psychiatry, 30(3): 449-454.

48. Yoshitake, T., Yoshitake, S., Fujino, K., Nohta, H., Yamaguchi, M. and Kehr, J. (2004). High-sensitive liquid chromatographic method for determination of neuronal release of serotonin, noradrenaline and dopamine monitored by microdialysis in the rat prefrontal cortex. Journal of Neuroscience Methods, 140(1-2):163-168.

49. Ahmed, N.A., Radwan, N.M., Al-Zahaby, A.S. and El-Salam, M.A. (1997). Reserpine effects on neurotransmitters in chick heart during growth. Journal of Physiology-Paris, 91(2): 81-90.

50. Carlsson, A., Hillarp, N.A. and Waldeck, B. (1963). Analysis of the $\mathrm{Mg}^{++}$-ATP dependent storage mechanism in the amine granules of the adrenal medulla. Acta Physiological Scandinavica. Supplementum. 6(1): Suppl 215:1-38.

51. Lohoff, F.W., Lautenschlager, M., Mohr, J., Ferraro, T.N., Sander, T. and Gallinat, J. (2008). Association between variation in the vesicular monoamine transporter 1 gene on chromosome $8 \mathrm{p}$ and anxiety-related personality traits. Neuroscience Letters, 434(1): 41-45.

52. Wessling, A. and Ramsberg, J. (2008). The review of antidepressants: the Dental and Pharmaceutical Benefits Agency. Solna: TLV.

53. Bannerman, D.M., Niewoehner, B., Lyon, L., Romberg, C., Schmitt, W.B., Taylor, A., Sanderson, D.J., Cottam, J., Sprengel, R., Seeburg, P.H. and Köhr, G. (2008). NMDA receptor subunit NR2A is required for rapidly acquired spatial working memory but not incremental spatial reference memory. Journal of Neuroscience, 28(14): 3623-3630.

54. Novak, P.H., Moessler, H., Gusev, E.I. and Guekht, A.B. (2009). Cerebrolysin in vascular dementia: a randomized, placebo controlled study. Alzheimer's \& Dementia: The Journal of the Alzheimer's Association, 5(4): 249.

55. García, E.H., Guzmán, D.C., Olguín, H.J., Jiménez, F.T., Acosta, E.N., Rioja, F.P., Mejía, G.B., Ruíz, N.L. and Del Angel, D.S. (2011). Effect of cerebrolysin on the levels of glutathione and 5-HT in different regions of rat brain in presence of dantrolene. Biomedicine \& Aging Pathology, 1(3): 169-174.

56. Bradham, C.A., Plümpe, J., Manns, M.P., Brenner, D.A. and Trautwein, C. (1998). I. TNF-induced liver injury. American Journal of Physiology-Gastrointestinal and Liver Physiology, 275(3): G387-G392 
57. Khalil, R.B. and Richa, S. (2011). Thyroid adverse effects of psychotropic drugs: a review. Clinical neuropharmacology, 34(6), pp.248-255.

58. Alderson, L.M. and Baum, M.J. (1981). Differential effects of gonadal steroids on dopamine metabolism in mesolimbic and nigro-striatal pathways of male rat brain. Brain Research, 218(1-2): 189-206.

59. de Souza Silva, M.A., Mattern, C., Topic, B., Buddenberg, T.E. and Huston, J.P. (2009). Dopaminergic and serotonergic activity in neostriatum and nucleus accumbens enhanced by intranasal administration of testosterone. European Neuropsychopharmacology, 19(1): 53-63.

60. Xie, J.P. (1989). The Overview Research of (Na+-K+)-ATPase. Sheng Wu Hua Xue Yu Sheng Wu Wu Li Jin Zhan, 16(4): 256-257.

61. Teng, J., Xu, Z., Zhang, J. and Li, J. (2014). Effect of yizhitongxuan decoction on learning and memory ability, Gaq/11 expression and $\mathrm{Na}^{+}-\mathrm{K}^{+}-$ATP enzyme activity in rat models of Alzheimer's disease. Journal of Traditional Chinese Medicine. 34(4): 470-476. 